\section{EMBRYRIDDLE \\ Aeronautical University}

SCHOLARLY COMMONS
International Journal of Aviation, Aeronautics, and Aerospace

7-7-2018

\title{
A Comparison of the Strengths and Weaknesses of Small-Format Aerial Photography Platforms
}

Jeremy W. Aber

Middle Tennessee State University, jeremy.aber@mtsu.edu

Tyler A. Babb

Middle Tennessee State University, tyler.babb@mtsu.edu

Douglas E. Campbell

Middle Tennessee State University, Douglas.Campbell@mtsu.edu

Kevin M. Corns

Middle Tennessee State University, Kevin.Corns@mtsu.edu

Follow this and additional works at: https://commons.erau.edu/ijaaa

Part of the Aeronautical Vehicles Commons, and the Aviation Commons

\section{Scholarly Commons Citation}

Aber, J. W., Babb, T. A., Campbell, D. E., \& Corns, K. M. (2018). A Comparison of the Strengths and Weaknesses of Small-Format Aerial Photography Platforms. International Journal of Aviation, Aeronautics, and Aerospace, 5(3). https://doi.org/10.15394/ijaaa.2018.1246

This Article is brought to you for free and open access by the Journals at Scholarly Commons. It has been accepted for inclusion in International Journal of Aviation, Aeronautics, and Aerospace by an authorized administrator of Scholarly Commons. For more information, please contact commons@erau.edu. 


\section{A Comparison of the Strengths and Weaknesses of Small-Format Aerial Photography Platforms}

\section{Cover Page Footnote}

This project was supported in part by the NASA-Tennessee Space Grant Consortium. 
Small-format aerial photography (SFAP) has become increasingly important to many fields in recent years. This kind of photography refers to a broad range of aerial platforms and camera types employed to collect aerial imagery of the earth's surface, but typically it is used in reference to low altitude image capture with the use of smaller, consumer-grade cameras as opposed to scientific sensors. This fills a niche between ground-based observations and space-based satellite imaging, and the primary benefit is the generation of high resolution imagery of localized phenomena such as local landforms, agricultural fields, human-built structures, and human activities. Another major benefit of these approaches are that some of the most commonly used platforms, unmanned aerial vehicles (UAVs) and tethered kite and blimp platforms (referred to as kite aerial photography, or KAP), are relatively easy to operate and quick to set up in most cases. Unlike satellite systems, which have comparatively low spatial resolution and may take days or weeks to collect repeat imagery of a location, these SFAP platforms have the potential to collect high-resolution imagery and gather repeat imagery at later dates much faster. Like any aerial imagery, SFAP is valuable because it helps to provide a new perspective on the spatial distribution of phenomena not available from normal human perspectives. With the widespread availability of geographic information systems and remote sensing software, this aerial view can be quantitatively analyzed and used to better understand both natural and human behaviors and the interactions between the two.

There are a large number of applications and industries where SFAP imagery is either typical or growing in popularity today, including agriculture, environmental monitoring, engineering and planning, intelligence, accident scene reconstruction, and many others. Wildlife monitoring is one area where SFAP is being used more and more, as traditional population count methods can be resource intensive (Bryson, Johnson-Roberson, Murphy, \& Bongiorno, 2013; Fraser, Carlson, Duley, Holm, \& Patterson, 1999; Gonzalez et al., 2016; Linchant, Lisein, Semeki, Lejeune, \& Vermeulen, 2015). Other environmental topics include vegetation monitoring, an area of work that has broad applications in the study of the environment as well as the agricultural industry (Aber, Aber, \& Leffler, 2001; Aber, Sobieski, Distler, \& Nowak, 1999; Berni, Zarco-Tejada, Suárez, \& Fereres, 2009; Laliberte, Herrick, Rango, \& Winters, 2010). The study of landforms and erosional processes are also applications where the use of SFAP has been applied, allowing for greater understanding of Geoscience topics as well as a better understanding of erosional processes for improving agricultural soil conservation (Aber \& Gałązka, 2000; Boike \& Yoshikawa, 2003; d'Oleire-Oltmanns, Marzolff, Peter, \& Ries, 2012; Eltner, Baumgart, Maas, \& Faust, 2014; Marzolff \& Posen, 
2009; Ryan et al., 2015; Smith, Chandler, \& Rose, 2009). Other applications include human topics with as broad a range as identifying unmarked graves in a potter's field, archaeologic data collection, and assessing conditions during humanitarian emergencies and natural hazard response (Aber, Aber, \& Pavri, 2002; Adams \& Friedland, 2011; Sklaver, Manangan, Bullard, Synberg, \& Handzel, 2006; Verhoeven, 2009).

UAV-based platforms are primarily to thank for the recent explosion of SFAP use, but the collection of SFAP imagery is far older than UAV technology. In fact, it predates human-crewed flight altogether, with some of the earliest aerial images having been taken not long after the invention of photography. Early aerial photographers used hot air balloons and kites to lift their cameras above the ground. One of the most famous early photographers was Gaspard-Félix Tournachon, known popularly as Nadar, who used a hot-air balloon to take aerial images of Paris (Frizot, 1998). The earliest known use of a kite platform for lifting a camera was undertaken by Arthur Batut in the late 1880s, who used a camera equipped with an altimeter and fuse for triggering the shutter (Benton, 2010). In the late 1800s and early 1900s, hot-air balloons, blimps, and kites were all regularly used for the collection of SFAP imagery since these were the only options for collecting this kind of information. Most aerial imagery switched to plane-based collection platforms following the development of flight in the 1920s and 30s (Hart, 1982).

Once airplanes began employing aerial photography, the tethered approaches to imagery collection were more or less non-existent outside of a few individuals who continued to use the technique (Beauffort \& Busariez, 2010; Hart, 1982). In the 1980s and 90s, interest began to rise in the use of tethered platforms, in part due to a rediscovery of some of the advantages of the SFAP approach when compared to plane- and satellite-based imagery collection. More recently, technological advances made a variety of UAV platforms into viable sources of SFAP, and UAVs have become so commonplace that we now live in what is described as a "Drone Age" ("Unmanned aerial vehicles," 2015).

The idea to remotely pilot an aircraft is not a new one, but it has only been in the past few decades that technology has caught up enough to make the idea a practical reality. The earliest attempts were associated with military technology, beginning with unmanned balloon bombings during the Austria Italy war and unmanned winged aircraft experiments during World War I (Cornelisse, 2003; Scientific American, 1849). Attempts to create viable unmanned platforms were largely unsuccessful until the latter part of the $20^{\text {th }}$ century, with many experimental programs failing due to technology not being up to the task or because of cost or 
reliability issues (Slattery \& Whittle, 2013). During most of the $20^{\text {th }}$ century, interest in and use of UAV technologies was mostly cyclical, corresponding to wartime needs and waning in times of peace. The big military breakout was the General Atomics MQ-1 Predator, a design first flown in 1994 which has since played a significant role in U.S. military operations in the $21^{\text {st }}$ century. The Predator marked the real sustained use of military UAV technology. The MQ-1 was not retired until March 9, 2018, and it has been replaced by more advanced designs (Donald, 2018).

Smaller, consumer-based UAV flight has roots in model aircraft hobbyists. Fixed wing model aircraft have been built and flown for many decades, but custombuilt multi-rotor hobby UAVs emerged during the late 1990s and early 2000s as technology became more advanced, lighter, and cheaper. Since 2010, multiple companies have released consumer grade ready-to-fly multi-rotor platforms as well as fixed-wing designs that are capable of capturing imagery and video, along with many other technological capabilities such as improved auto stabilization and collision avoidance features. Since then the UAV market, including both consumer and professional applications, has become a significant industry, estimated to have an impact of more than $\$ 82$ billion by 2025 (Jenkins \& Vasigh, 2013).

UAVs have proven themselves to have enormous potential for the collection of SFAP and other data and are upending work practices in many industries by improving response times, data quality, and providing previously inaccessible views to problems. However, UAVs are not a panacea. Even with advances in technology, they will continue to have some restrictions on their use that make them impractical for specific applications. While older tethered platforms for collecting SFAP were largely forgotten after the introduction of airplane- and satellite-based imaging, it turned out that in some scenarios, a KAP approach provided opportunities not available to larger, more expensive platforms. UAVs fill a similar niche, as relatively low cost, localize sources of high-resolution imagery. Both KAP and UAV platforms have their pros and cons that make them more or less suitable for various applications. KAP platforms can help to fill in the gaps in some situations where UAVs are not ideal. Likewise, tethered KAP platforms may not be ideal for all image capture applications, and a UAV platform may be better suited. This article explores these SFAP platforms at a broad level and discusses the practical considerations of each in different areas. This discussion is primarily concerned with image collection for professional and scientific work rather than recreational video or media purposes, but many of the topics discussed apply to all tethered and UAV flight applications. 


\section{Comparing the Platforms}

The researchers investigated categories of SFAP collection platform types rather than specific brands or models of UAVs or kites. Given that UAV technology, in particular, has and will likely continue to advance at a rapid pace, a focus on specific models' capabilities would quickly become outdated. This article will consider fixed-wing UAVs (Figure 1), multi-rotor UAV copters (Figure 2), tethered kites (Figure 3), and tethered blimps lifted by gasses such as helium (Figure 4). In regards to UAV platforms, this article will focus primarily on the smaller-scale hardware commonly used for collecting SFAP. Larger UAV platforms exist, including military equipment used as reconnaissance and weapon platforms, but these will not be a part of the discussion.

In comparing the different SFAP platforms, there are various practical factors of their operation that must be considered. Some of these are physical factors, such as the capabilities and limitations of the lifting mechanism. Others relate to environmental factors like atmospheric conditions and the suitability of local sites for operation. In addition to these, imaging sensor options, hardware and continuing operation costs, and regulatory factors that affect how and where SFAP platforms can be legally operated are covered. While SFAP can be collected worldwide, the authors have the most experience collecting imagery within the United States, and the bulk of the regulatory discussion will focus on United States Federal Aviation Administration (FAA) regulations.

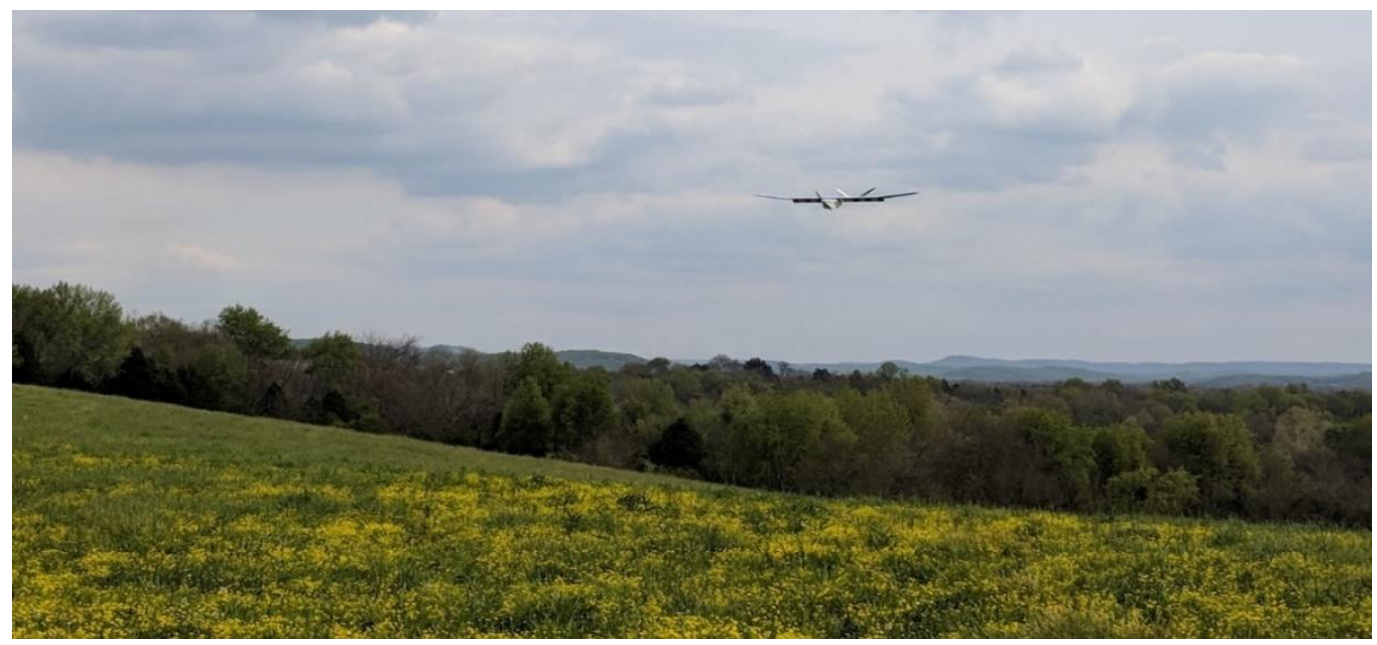

Figure 1. A fixed-wing UAV on final approach to land. 


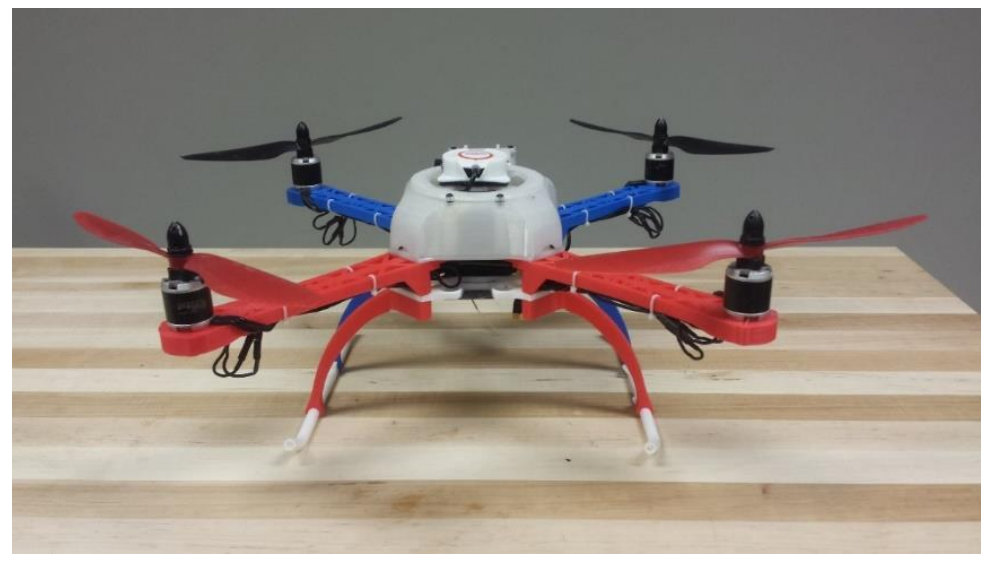

Figure 2. An example of multi-rotor UAV, in this case, a quad-copter.

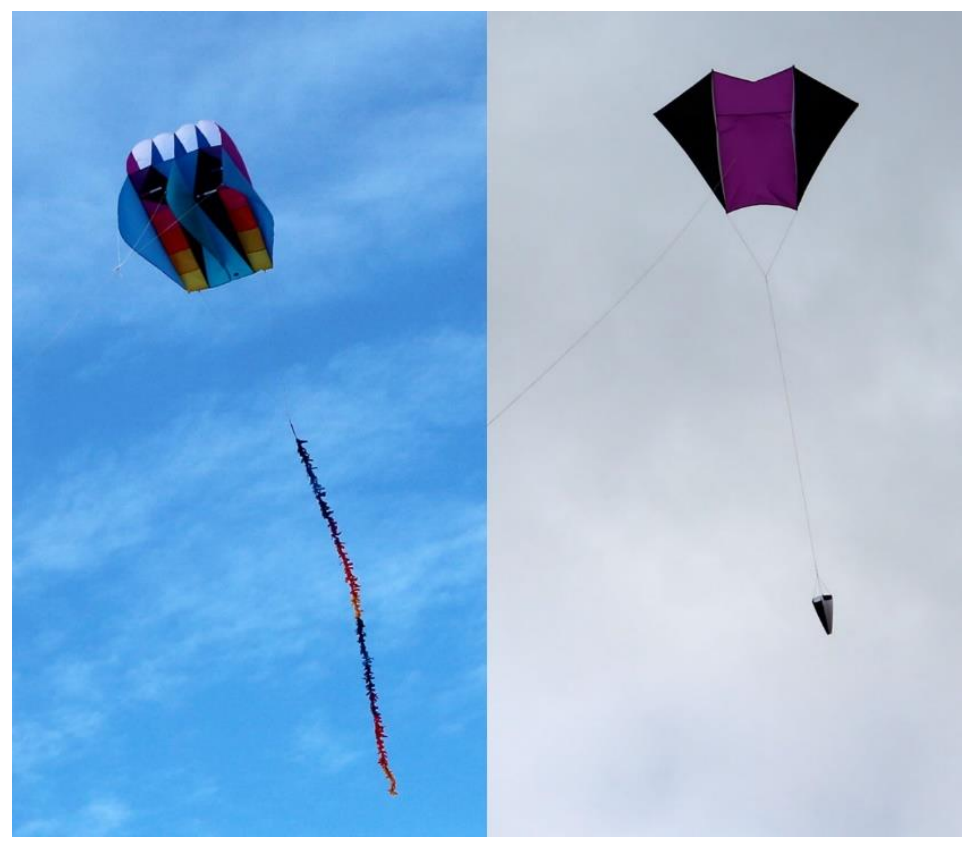

Figure 3. Two examples of tethered kites. The kite on the left is a soft kite that can fly in winds between 5 and $30 \mathrm{mph}$, although higher speeds of $15 \mathrm{mph}$ or more are necessary to lift a camera rig. The kite on the right is a rigid kite that has carbon fiber spars to add support. This allows the kite to fly and lift a camera rig in lower windspeeds of around 10 miles per hour or more. Higher windspeeds of $20 \mathrm{mph}$ or more can damage the carbon fiber spars. 


\section{Flight Characteristics}

All UAV platforms are essentially miniaturized versions of larger mechanized flight platforms, namely fixed-wing airplanes and multi-rotor helicopters. As such, the principles of flight are the same, only at a smaller scale. Typically, these smaller UAV versions are powered either by batteries connected to electric motors, or liquid fuels used to power small combustion engines. Fixedwing designs have flight characteristics similar to human-scale airplanes and work well for flying long, sweeping paths across a site to collect images. Multi-rotor UAV platforms are much more maneuverable, many of them capable of taking highly irregular flight paths if necessary, as well as being capable of flying in constrained environments.

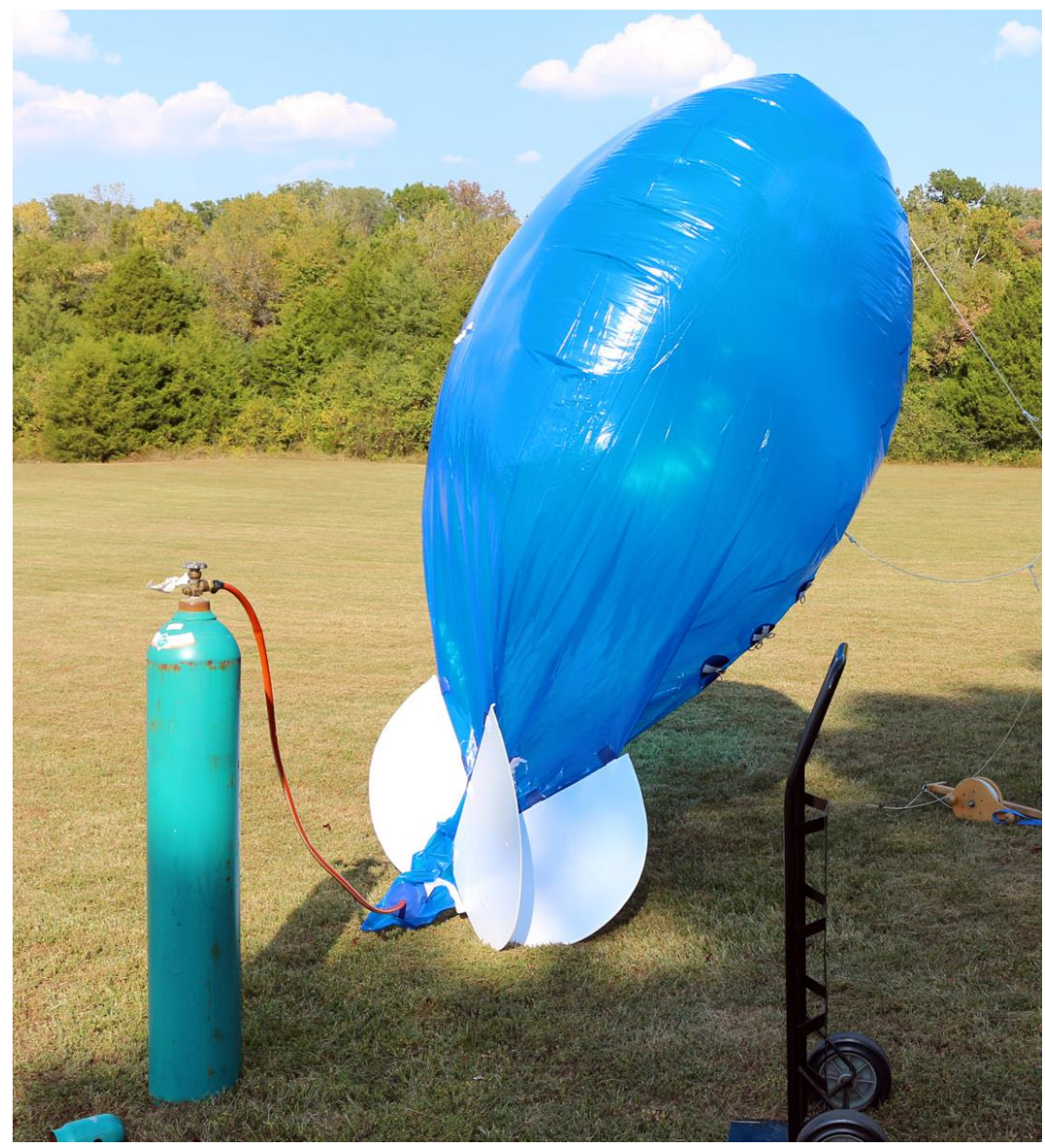

Figure 4. An example of a helium blimp being inflated before flight. When full, this particular blimp is thirteen feet in length (just under four meters) and holds approximately 300 cubic feet of helium (eight and a half cubic meters). 
Kites are wind-powered. The wind's push against the kite fabric is in opposition to the pulling of the fixed line, lifting the kite and its payload. Naturally, this means that a steady wind is ideal for the use of a kite platform. In contrast, blimps perform best in little to no wind, as they rely on lighter than air gas for lift, typically helium. Other lighter than air gasses such as hydrogen or methane could theoretically be used to lift a blimp, but they are not advisable as they are highly flammable (Aber, 2016). Both kites and blimps are tethered, or linked to the ground, and are therefore less maneuverable than UAV platforms in general, but some kites can be directed by the line, and all tethered platforms can be maneuvered by walking the line around a site. Some blimp manufacturers also produce platforms that are designed to be maneuvered like a zeppelin via radio control.

One of the largest differences between the platforms' lifting mechanisms is the length of flight time possible. UAV platforms are limited in how long they can fly by the energy required to lift them. Fixed wing designs generally have longer flight times, in many cases capable of flying for multiple hours depending on the size of the platform and the payload weight, and in the case of certain fixed-wing solar designs can potentially fly perpetually (Oettershagen et al., 2016). Small, ready-built multi-rotor UAVs typically max out at no more than 25 to 30 minutes under ideal conditions before they require a battery swap ("Best Drones," n.d.). All UAVs will have the longest flight time potential under ideal conditions, but heavier than standard payloads, extreme temperatures, and other factors can all negatively impact the length of the flight. More expensive and custom-built platforms may have longer or shorter flight times than the cheaper consumer models, it all depends on the specifics of the platform, the application for which it is outfitted, and environmental conditions. Some models may have liquid fuel powered generators onboard to extend the electrical charge. Other UAVs may be tethered by a cable that provides power, allowing them to fly as long as the power continues. For many applications, a 15 to 20-minute flight may be enough time to capture SFAP of a site, but for larger sites, or ones that require heavier specialized imaging equipment, it may not be enough. In those cases, grounding the UAV to swap in spare batteries, or employing multiple UAVs may be necessary to complete the job.

Some applications benefit from an uninterrupted aerial perspective that is longer than 15 to 20-minute flight time, and the tethered platforms are more reliable at providing this, as they mostly have no flight time limit. Windspeeds can change unexpectedly, but under ideal conditions, a kite or blimp can fly as long as the operator desires. With no limit on the flight time, SFAP collection is instead limited 
primarily by the imaging sensor's power source, which is often capable of taking photos for a more extended period than typical a UAV battery can last.

While flight is limited in time, it is also limited in the distance. Tethered platforms are limited by the length of their tether, but UAVs also have limitations. Both fixed-wing and multi-rotor designs are capable of flying further than tethered platforms regarding distance from the operator, although power source capacity, atmospheric conditions, ground visibility at the site, and the capabilities of the specific flight control transmitter in use can all play a role in the exact distances. However, while a UAV may be capable of flying farther than a tethered kite or blimp, current FAA regulations, discussed in detail later, limit commercial UAV flights without a waiver to remain within visual line of sight of the remote pilot or a visual observer (Federal Aviation Administration, 2018a).

Sound is another flight characteristic of note. While kites can sometimes make a flapping noise in high or variable winds, both tethered approaches are quiet in general. UAV platforms often produce a loud buzzing or humming noise generated by motors or spinning rotors. For some applications such as wildlife monitoring, this could be a severe issue, as the noise, along with color and movement, might frighten away the wildlife to be monitored (Mulero-Pázmány et al., 2017; Rümmler, Mustafa, Maercker, Peter, \& Esefeld, 2015). In other applications that involve collecting imagery of public social or cultural events, the noise of a UAV might be distracting and undesirable. Noise pollution was one of the reasons that UAV flights are prohibited in Yosemite National Park and later across the entire National Park System (National Park Service, 2014). Of course, the higher the altitude of the platform the less likely the noise will be audible on the ground, but UAVs do have a regulated flight ceiling (discussed later), and it is a factor to consider.

Beyond imaging, the lifting platforms commonly used for collecting SFAP are also used in the atmospheric study. In the case of kites, blimps, and balloons, their use in studying the atmosphere has a long history dating back to the late $19^{\text {th }}$ century (Ohring, 1964). While UAV platforms may be capable of carrying out some of this work, they have been found to be less than ideal in some situations. This is due in part to their relatively short flight times, but also because multi-rotor UAVs produce thrust to stay aloft, which can interfere with collecting an unbiased atmospheric sample. 


\section{Atmospheric Considerations}

Since all of these platforms involve flight, practical considerations of the atmosphere and weather must be discussed. Generally speaking, clear skies during midday are preferable for achieving reasonable lighting conditions for SFAP imagery. Wind is apparently necessary for the operation of kites, but too much wind can be trouble. Different kites are designed with different windspeeds in mind, with some kites specifically for use in light winds of 5 to $12 \mathrm{mph}$ and others capable of flying in speeds as high as $30 \mathrm{mph}$ (Conrad, n.d.). Stronger lines are necessary for lifting kites in higher windspeeds, and if the speed is high enough or strong gusts are experienced, the line or the kite may become damaged, leading to a crash. The camera platform can be bounced around by gusty wind as well, leading to blurry images.

Wind can also be a factor for UAV flight. UAVs can fly in many conditions, but high or gusty winds can be problematic, leading to difficulty in capturing images due to the platform not being stable in flight. This can also reduce flight time, as the UAV may have to use more energy to return to its path and work against the wind. Blimps are only advisable for operation in windspeeds of five miles per hour or less, which means that some areas that experience consistent wind, such as coastal regions, are not ideal for blimp operation.

Temperature and air density are more factors to consider. Extreme high temperatures can affect flight potential due to changes in air density, and extremely low temperatures can negatively affect battery life. For kites and blimps, temperature is less of an issue, as their lifting capacity is mostly affected by the presence or absence of wind. Camera battery life can also be affected by these conditions, and extreme highs could negatively affect the electronics employed in the imaging process. UAV platforms have a harder time than the tethered platforms in temperature extremes. Extreme high temperatures may make flight less efficient or impossible because of low air density, and low temperatures will affect battery performance reducing UAV flight time. UAVs that use a form of liquid fuel to power an internal combustion engine may be less affected by low temperatures, but extreme temperatures can be problematic for UAV platforms in general. While extreme highs and lows may not be an everyday issue for many operators, there are applications where this is a serious concern; Fraser et al. (1999) provide an example of one of these situations where a kite was employed to monitor penguin populations in Antarctica. The surface elevation at the site of operation is also a factor. Collecting SFAP in mountainous regions may be more difficult for both 
tethered and UAV approaches due to lower air densities regardless of air temperatures.

Awareness of severe meteorological conditions is essential to all types of flight, including both UAV and tethered platforms. Flight during severe weather is unadvised and impractical at best. The risk of damage to equipment and injury to operators from rain, hail, high winds, and lightning is too high to justify SFAP image collection. In any case, the quality of the imagery would likely be suboptimal due to visibility issues stemming from lighting and precipitation factors. In situations where light precipitation is occurring in the absence of other severe weather phenomena, it may be possible to fly, but this is unadvised for the same risks of damage or injury to equipment or operator.

Even when conditions appear clear and ideal for image capture, awareness of the weather is vital as a so-called 'bolt from the blue' can strike as far as 25 miles from a thunderstorm (Sohn, 2011). These events are rare but have proved fatal in the past, so it is important to be aware of the weather both for the sake of equipment and operator safety. The popular retelling of Benjamin Franklin's kite-based lightning experiment may not be entirely accurate to the historical events, but regardless, there is no need to recreate it today (Benjamin Franklin and the Kite Experiment, 2018).

\section{Site Conditions}

All of the platforms discussed in this article benefit from having an open space for flight. This is useful on two levels, the first being that it makes line of sight contact with the platform easier, which is a safety concern and FAA regulatory requirement for operations conducted in the United States. It is possible to fly multirotor UAVs in relatively confined areas, but a loss of line of sight with the UAV can quickly become a risk for equipment damage and dangerous to operators and bystanders. Fixed wing UAVs typically cannot operate in confined areas only due to their flight profiles, and tethered platforms run the risk of having their lines become entangled on obstructions meaning that these approaches more or less require open space for operation.

The other main reason that open spaces are valuable is that contact between environmental obstructions and SFAP platforms is dangerous. It leads to crashes and equipment damage, and could potentially damage utilities like electrical or communications equipment. This risk tends to be higher for tethered platforms merely because they are physically tied to the operator. UAVs can often fly around objects that do not obstruct line of sight such as light posts or trees without much 
risk of injury to equipment or individuals on the ground, but a kite in the same situation can easily become entangled. There is a potential for the total loss of otherwise functioning equipment, as a kite and camera rig tangled in a tall utility pole or at the top of a large tree may be unrecoverable.

For many SFAP applications like agricultural monitoring, finding an open space to operate is not an issue, but other uses may not have that luxury. As an example, imagery for real estate purposes may be needed in areas where there are many environmental obstructions such as trees and utility lines. In those cases, multi-rotor UAV platforms may be the only practical solution.

\section{Operation Considerations}

Although the operation of these platforms is relatively straightforward, each has their unique considerations and challenges that must be considered. For operations using a blimp, the filling of the blimp with helium, attaching the camera, and raising/lowering the blimp is all very straightforward, and a blimp can be operational from unpacking to collecting images in under 20 minutes. Likewise, flying a kite is an activity that almost anyone is capable of doing, and is similarly quick to set up. The primary operational factor that affects tethered platforms is monitoring atmospheric conditions. In particular, kite flying is not unlike fishing, with constant feedback from the wind coming through the kite line. As the wind rises and falls, the line must be managed to maintain safe flight, and turning one's back for even a minute can lead to a crash if the wind unexpectedly drops.

Because UAV platforms function through the some of the same principles as manned airplanes and helicopters, their operation requires a more specialized knowledge than operating a kite. Especially for fixed-wing UAVs, the operator simply has to know how to fly, something that can take a significant investment of time and resources to master. For commercial use of a UAV, a Remote Pilot certificate is required by federal regulations and will be discussed in more detail a later section. Multi-rotor UAVs tend to be easier to pick up because most multirotor platforms have computer-controlled stabilization functions that make them easier to control. UAVs may also have the capability to be preprogrammed with flight patterns that require little user input to carry out, making image capture more automated. These functions can be risky though, as they may lead novice operators with little flight experience to overestimate their abilities. If stabilization were to fail or sudden strong gusts of wind were to occur, novice pilots might find themselves in trouble. There is no shortage of stories of novice UAV pilots crashing 
or injuring bystanders, and safe and effective operation requires training and practice.

While UAVs, kites, and blimps can all theoretically be operated by a single individual, a team of two or three is recommended for safer and more efficient operation. With tethered operations, having a second person allows for one to monitor and control the lines, while the second operates the camera remotely. During the takeoff and landing phases, having one person control the line while the other handles the attachment/removal of camera equipment and the kite or blimp itself is almost essential to smooth operation. With UAV platforms, having a second person present adds level of safety during flight operations. While one person controls flight, the second person acts as a visual observer to reduce the remote pilot's workload and provide logistical support in regards to equipment issues. For all platform types, a second set of hands and eyes simply makes for safer and faster deployment and operation of equipment.

Even with a small team operating, unexpected events can still occur. The wind can suddenly shift, a kite might tear from stress, or some hardware component may fail on a UAV. In these instances, it would be nice to have some fail-safes as a backup. Generally speaking, tethered platforms do not have much capacity in this area, but UAVs may offer some solutions to deal with emergency situations. Many multi-rotor UAVs offer some amount of stabilization during flight and may be able to automatically recover from unusual attitudes, assuming power still exists and the rotors are not physically damaged.

Additionally, some platforms offer a recovery system such as a parachute, which can soften the impact with the ground and hopefully minimize damages to equipment and anyone who happens to be in the vicinity of the crash site. Even with the potential for poor piloting causing issues, UAV platforms may in some ways be safer than the tethered options because of these fail-safes. Tethered platforms are simpler to fly, which may lead to fewer emergency situations in the first place.

\section{Imaging Sensors}

One of the most exciting things about SFAP is the flexibility in hardware configurations available to users. Not all imaging needs are the same, and a custom setup can be built to address specific data collection goals. UAV cameras are typically attached directly to the flight platform, and while some models may only be compatible with manufacturer-specific imaging sensors, many UAV platforms allow for customization. Figure 5 shows an example of a multi-rotor UAV imaging 
setup. Kite platforms' cameras typically hang from the kite line, not the kite itself, while some blimp models allow for the camera to be hung from the underside of the blimp as opposed to the line. Many tethered approaches require user customization in regards to imaging sensors. Some blimp manufacturers offer allin-one packages, but others sell only the blimp sans camera. For kites, the closest thing to a complete package are kits to build camera rigs, but these all require customization to accommodate the specific camera used. Figure 6 shows an example of a kit-built camera rig that can be connected to a kite line or blimp that was customized to mount a specific camera and shutter trigger mechanism.

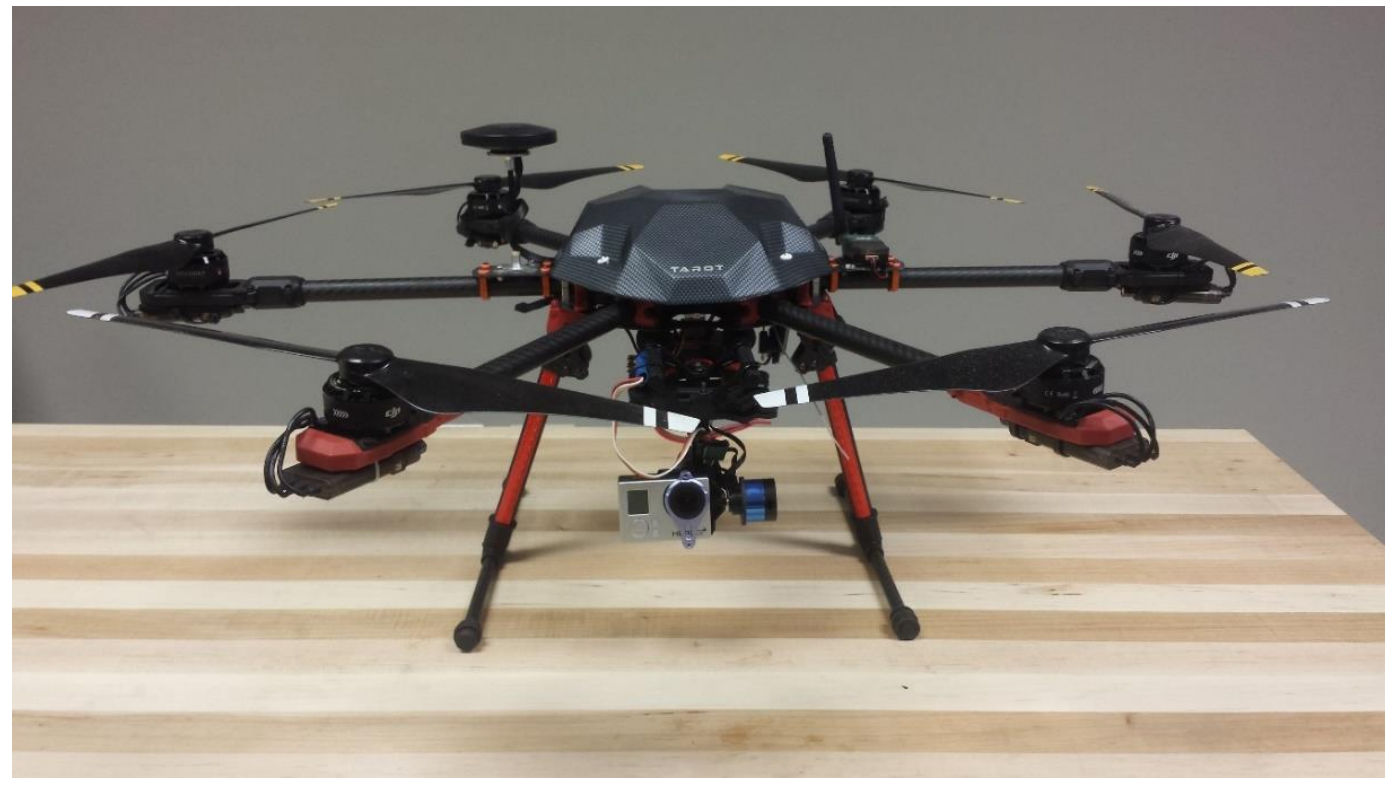

Figure 5. An example of a UAV with a gimbal mounted camera. This particular UAV is carrying a GoPro Hero3+ camera.

Until the widespread adoption of digital cameras, mechanical methods were required to trigger camera shutters, but now that virtually all imaging is done via digital means, controlling the camera from the ground is significantly easier. Some cameras are sold specifically to be used for SFAP applications, such as Tetracam's lineup of infrared sensor options, and are already designed to accept electronic trigger inputs. Other off-the-shelf cameras need software modifications, such as the custom Canon Hack Development Kit (CHDK) firmware that can be installed on many Canon models allowing the USB interface to act as a trigger. CHDK also allows for user scripting, which can significantly extend options for imagery collection beyond simply triggering the shutter (CHDK Wiki, 2018). Others setups may employ an infrared LED that pulses, triggering a camera's preexisting remote 
shutter mechanism. Some camera systems allow for continuous shooting or shooting at a defined interval. Embedded UAV systems may also offer similar options to users for automated or manual image collection. Whether the shutter is controlled from the ground or set to run automatically is up to the user and the needs of the specific application, and the options available are more or less consistent across all lifting platforms.

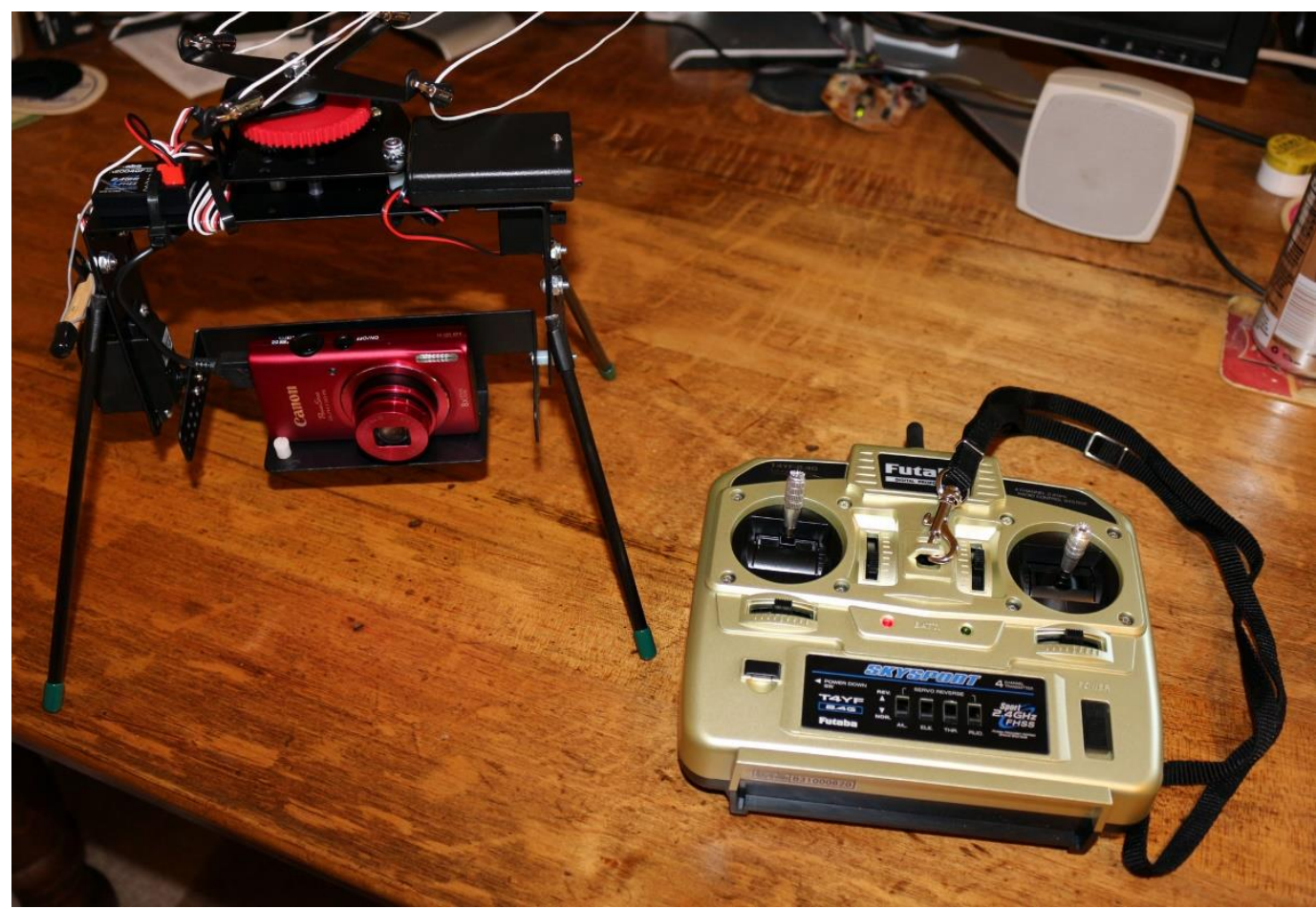

Figure 6. An example of a customized kit-built remote camera rig carrying a Canon PowerShot ELPH 130IS for use with tethered platforms.

In addition to controlling the shutter, some setups are capable of remotely aiming the camera independently of the lifting platform. Others are fixed relative to their lifting platform and do not provide any options in this regard. A fixed camera angle is common on fixed-wing UAV platforms, as they are often used to sweep across a site specifically to collect vertical imagery. Multi-rotor UAVs and tethered platforms may or may not offer camera angle controls. As an example of a camera rig used with tethered platforms, the custom setup in Figure 6 is capable of rotating a full $360^{\circ}$ and can adjust the camera angle from the horizon to straight down. 
The choice of camera will always depend on the imagery needs, but the camera also influences larger platform decisions related to weight and power. Some setups will have their separate power sources, while others will draw power directly from the same source as the lifting mechanism. For tethered platforms that require no electric power for flight, an external source is a necessity, but with UAVs either option is possible. Drawing power from the same source that lifts the UAV will naturally drain the batteries faster and reduce flight time, but the additional weight of an extra battery will do the same. It is worthwhile to do some testing with specific UAV setups to determine which approach would be most efficient. Also, while quality imaging sensors have shrunk dramatically over the years, they may not be good enough for all applications. In particular, imagery intended for use in scientific research may require more extensive, higher-quality lenses and specialized sensors not available in lightweight packages such as a GoPro or consumer point and shoot cameras.

\section{Costs}

The costs involved in SFAP platforms have two levels of consideration: the initial startup costs and continued operating costs. For startup costs, tethered platforms are inexpensive. UAV platforms start on the low end in a similar price range, although costs can be much higher depending on the specific platforms involved. Naturally, costs are always changing. Different suppliers of equipment that can be used for collecting SFAP will charge different amounts and may have sales or discounts for educational institutions. All numbers mentioned here are rough estimates of the current cost as of the time of writing.

For kite platforms, the most expensive portion is the setup phase. Building a suite of hardware that includes a variety of kites for different wind conditions, cameras, remotely controllable camera rigs and batteries, and other assorted hardware helpful for operating kites will likely cost between $\$ 1,500$ and $\$ 3,000$. The addition of specialized imaging sensors such as one of Tetracam's infrared cameras will add significantly to the cost, but the core components for collecting SFAP via kite are relatively inexpensive. For blimps, the cost can be similar if a basic blimp is purchased in place of the kites. More expensive blimp platforms exist though, and the costs for more advanced blimp platforms in a ready to fly state can run as high as $\$ 30,000$ or more. If blimps are intended to be stored in an inflated state, a large enclosed trailer for transport will likely be necessary, raising the startup costs significantly. 
The startup costs for UAVs can be similar to those of a kite or blimp platform. On the low end, the UAV itself, any additional camera or imaging sensors, and other equipment related to operation could start in the same $\$ 1,500$ to $\$ 3,000$ range as the tethered platforms. Typically, the startup cost will be higher and can go considerably higher in the tens of thousands of dollars' range depending on the platform in question. Some UAV systems can run into the millions of dollars, but many can be purchased for significantly less, and custom building a setup will likely reduce the cost.

The startup costs are only one factor to consider. Continued operation of any of these platforms will involve upkeep. Kites tend to be the cheapest in this regard. Replacement of batteries for operating cameras, camera rig servos, and remote controllers are all relatively inexpensive, and the kite's flight is free. Other hardware like cameras and tools may need to be replaced periodically, and crashes and accidents can lead to premature equipment failure, but on the whole, once a kite setup is in place, the continued operating costs are minimal.

Blimps are mostly the same as kites in regards to operating cost, except the lifting gas. Helium is the most common and can be quite expensive, particularly outside the United States. Although the costs fluctuate over time, current rates for a 300 cubic foot tank of balloon-grade helium in the US may run anywhere from two to three hundred dollars. After a flight, an inflated blimp can either be stored in an inflated state or deflated until its next use. Storing an inflated blimp can be problematic simply because of their size. For example, transporting the blimp seen in Figure 4 in an inflated state would require an enclosed trailer large enough to hold a car. Despite the logistical issues, storage of a blimp while inflated is preferable to releasing helium into the atmosphere, and the rationale is twofold. First, helium is a limited resource used for applications like operating fMRI machines and as a part of the production of computer chips and releasing the gas after a flight could be considered wasteful. Secondly, if helium is released after each flight, more helium must be purchased for the next flight, increasing the cost of operation.

The continuing costs for UAV platforms are a bit more complicated and expensive. Because most UAVs use batteries to power their lifting mechanism, more batteries are required to be used more often during operation. As anyone with a smartphone can attest, batteries will lose charging capacity over time, reducing UAV flight times as they age. This means that more batteries will be used in UAV operation than in kite or blimp setups, leading to higher operating costs over time. On commercial flights, spare lithium-ion batteries are allowed only as carry-ons, 
and some of the batteries used by larger UAVs are prohibited (Federal Aviation Administration, 2013). This means that long-distance transport of equipment can be problematic. Slower or more expensive methods of transport may be required, or the purchase of new batteries at upon arrival at the site may be necessary, driving up costs.

Kite and blimp technology are mature, having been designed, operated, and refined over more than a thousand years in the case of kites and more than 200 years in the case of balloons and blimps (Gillispie, 1983; Hart, 1982). There are few significant changes likely to occur to kite and blimp design in the $21^{\text {st }}$ century that would make it worthwhile to upgrade from an existing kite. On the other hand, UAVs, as they are employed today, are a recent technology, and the pace of change is rapid. While batteries are unlikely to suddenly become dramatically more efficient anytime soon, every other component of the UAV ecosystem is improving and changing at a rapid pace, from advances in materials to software improvements. In practice, this means that while UAV systems may continue to be functional after multiple years of operation, they may not be as cost-efficient to operate as they were when new. This could be considered a form of operational obsolescence because it has partially to do with common equipment failures over repeated use, but also because of some manufacturers' design with a limited lifespan in mind, like a refrigerator that only lasts ten years before failing.

UAV operational costs are also related to the progress of UAV technology in general. Each new release of UAVs promises lower weight, longer flight times, and more effective designs overall, and given the pace of improvements, they often deliver on their promises. A UAV from five years ago may still operate, but compared to a newer model, it may not make any sense to continue operating given the improvements in technology. At the same time, UAVs are not just about hardware, there is a strong software component to most platforms, with autostabilization, autonomous navigation capabilities, and safety procedures for recovering from in-flight failures all being possible. Older platforms may not offer these capabilities. Older UAV platforms may fly just fine, but they may not be as efficient, offer fewer capabilities, and may not be capable of interfacing with newer hardware. All of this leads to a need for more frequent hardware upgrades to stay current with optimal equipment, which adds to the overall cost of operation. As more mature, less complicated platforms, tethered kites and blimps will typically offer lower startup and continued operation costs when compared to UAV platforms. 


\section{Regulatory Factors}

Within the United States, there are significantly different regulatory concerns for tethered and UAV platforms. Tethered platforms do have FAA guidance for safe operation, but they are liberal when compared to those that govern UAV flight. Tethered platform regulations can be found under 14 C.F.R. §101.11101.19 (Federal Aviation Administration, 2018b). These state that tethered platforms (including virtually all tethered SFAP platforms) must operate 500 feet below the base of any clouds, must not go above 500 feet from the surface of the earth, must have more than three miles visibility, and cannot operate within five miles of any airport without providing 24 hours' notice to the local airport authority. These regulations apply whether the operator is a hobbyist or engaging in operation for profit.

UAV flight for hobbyists follows more or less the same restrictions as tethered platforms do, although they operate under Subpart E - Special Rule for Model Aircraft found in 14 C.F.R. $§ 101.41$ (Federal Aviation Administration, 2018c). For hobbyists to be legally compliant with FAA regulations, hobbyists must register with the FAA as a "modeler," and put their registration number on their UAV. There is a five dollar registration charge per aircraft, and the registration is valid for three years. Registration is required for any UAV between 0.55 pounds in weight (250 grams) and 55 pounds $(25 \mathrm{~kg})$. Small toy UAVs are generally below the weight requirement, but any platform large enough to carry a camera or other imaging sensor will typically fall into this range and need to be registered. As of January 2018, the FAA has registered over one million drones, approximately $88 \%$ of which belong to hobbyists (U.S. Department of Transportation, 2018).

Commercial UAV operation has more significant regulatory guidance that must be followed; the full list of which can be found in 14 C.F.R. $\S 107$ Small Unmanned Aircraft Systems (Federal Aviation Administration, 2018d). These regulations apply to any UAV that has a takeoff weight of more than 0.55 pounds and less than 55 pounds that is operated for any use beyond hobby flight. This covers both for-profit commercial operation and not-for-profit work such as academic research. This article will not attempt to reproduce every aspect of these regulations, and operators should read 14 C.F.R. $§ 107$ Small Unmanned Aircraft Systems to ensure they are compliant. Some of the more noteworthy factors are that UAVs must be operated via line of sight, rather than using a remote camera feed for avoiding manned aircraft, pilots must be 16 years of age, operation is only allowed during daylight hours, they must not exceed a groundspeed of $100 \mathrm{mph}$, operate above 400 feet above ground level, and the operator must have a remote 
pilot airman certificate. Additionally, UAV equipment and atmospheric conditions must be checked prior to flight to ensure safe operation, flight must not take place above people unless they are directly participating in the operation or are shielded by a structure, and any accidents meeting certain criteria described by the regulations must be reported to the FAA no more than ten days after the incident. Other restrictions apply as well, such as respecting restricted airspaces near airports and other designated areas like the National Park System and the capital city of Washington D.C. (Federal Aviation Administration, 2017; Jarvis, 2014).

Obtaining a remote pilot certificate is not nearly as involved as a full pilot's license, but it still requires effort. First-time pilots must schedule an appointment with an FAA-approved Knowledge Testing Center and completed an initial aeronautical knowledge test. They must also complete FAA Form 8710-13 and pass a Transportation Security Administration security background check. For those who already hold a valid pilot certificate, they must have completed a flight review within the previous 24 months and take an online training course in addition to filling out the $8710-13$ form. This remote pilot certificate must be renewed every 24 months.

Internationally, different countries have different regulations describing legal flight options for both tethered and UAV platforms. In the European Union, regulations are not finalized but are likely to be similar in scope to US regulations. The European Commission has committed to having finalized and implemented regulations in place by 2019 , and have agreed that registration of UAVs, as well as requiring a real-time 'black box' system for all "dangerous" UAVs (European Commission, 2017; Fioretti, 2017). "Dangerous" is described as any UAV having the kinetic energy or more than 80 joules based on mass and maximum speed. Currently, UAV regulations may differ from one EU member state to the next.

Outside the EU and the US, some countries, states, or municipalities are incredibly restrictive, while others permit nearly unregulated flight. Adherence to local regulations is important to follow for legal and safety reasons. In countries that have few or no regulations, it remains important to follow common sense safety practices to avoid damage to equipment or injury to operators or bystanders.

Regulations are one of the places where tethered platforms have a major advantage over UAVs, as their operation is far less restricted in most situations. Additionally, there are many places in the United States where UAV operation is prohibited while kites and blimps are allowed, such as parts of the U.S. National Park System. The public perception of UAV flight can also be a hindrance to SFAP 
collection. Many people continue to have a negative impression of UAV operation, specifically law-enforcement surveillance activities (Kreps, 2016). With UAVs continuing use for military and law enforcement purposes, this public perception is likely to persist in the future. Kites and blimps tend to present a non-threatening image to onlookers. While these are not legal restrictions, they may make the relationship between operator and onlooker smoother and may open doors to land access that might otherwise be closed to SFAP operators.

\section{Conclusions}

Discussing some of these practical considerations should make it clear that each type of platform excels in some areas and is deficient in others. Ideally, an operator would have access to any platform necessary for the job types and conditions they are likely to encounter. People with a need for SFAP today often turn to UAVs because they are capable, exciting new technologies. However, it is worth investigating how tethered approaches might potentially be a better fit for specific applications. While they may be less maneuverable, kites and blimps have been used for more than a hundred years as sources of aerial imagery, and they stand out in some areas where UAVs fall short.

The major benefits of tethered platforms are increased flight times, the relative unobtrusiveness of operation, and relaxed regulatory restrictions. Both kites and blimps are capable of flying more or less indefinitely, assuming acceptable atmospheric conditions. They are easy to operate, quiet, and do not tend to raise privacy anxieties among bystanders the way a UAV might. Perhaps most importantly, they have far fewer legal restrictions governing their operation than UAV platforms. Kites and blimps can often be operated in locations where UAVs are prohibited, making a tethered approach the only option for SFAP in some circumstances.

However, tethered platforms often require far more do-it-yourself construction and modification to reach operational status, as there are fewer readyto-fly options on the market. This could be considered a positive or negative though, as customization allows the user to include the exact functionality desired. Tethered platforms are less maneuverable than UAVs and run the risk of having lines being caught in obstructions, necessitating a large open space for operation. They are also at the mercy of atmospheric conditions in a way that UAVs are not, as a kite cannot fly in the absence of wind, and a blimp cannot be used effectively in windy conditions. Kite and blimp technology is a highly refined, mature technology, but 
this means that it is unlikely that there will be any major technological breakthroughs in design moving forward.

The largest benefit of UAVs is that they are far more maneuverable than tethered platforms, particularly multi-rotor designs. This may make UAVs a better option for collecting SFAP in areas with more environmental obstructions, as they will be more capable of working in tight spaces. Some models also offer automated flight, with preprogrammed flight plans capable of being designed and run at the touch of a button. Operator attention and control is still necessary, as problems can arise during automated flight, but even in those cases, some UAV offer emergency fail-safes, like automatic recovery from uncontrolled flight or parachutes to lessen impact forces. UAVs' major drawbacks are that they tend to be harder to learn to fly, may cost considerably more regarding both the startup and continued operational costs, and have far more regulatory restrictions on their use than the tethered platforms.

In the future, the UAV ecosystem will continue to evolve with advances in technology and practices. Some of the negatives that have been discussed here may be mitigated at least in part by advances in materials, hardware design, and software. UAV platforms will continue to refine their designs and use of materials so that flight times can increase and flying can become safer, especially for operators with less experience. Imaging sensors will also continue to improve, with higher image quality coming from smaller, lighter packages that draw less power.

SFAP software and automation will continue to improve, both regarding controlling the hardware and in processing imagery. Photogrammetry, the branch of image processing that generates three-dimensional models from photographs, is a perfect example of this improvement (Egels \& Kasser, 2004). In recent years, advances in software have made photogrammetry significantly easier and faster to process, leading to an explosion of use across many fields based on SFAP imagery from both UAVs and tethered platforms (Aber \& Babb, 2018; Marzolff \& Poesen, 2009; Smith et al., 2009; Westoby, Brasington, Glasser, Hambrey, \& Reynolds, 2012). In regards to automated flight, the addition and refinement of sensors and software will continue to improve the autonomous flight capabilities of UAVs. They will remain restricted in some ways though, and if signals like GPS or other locational telemetry are degraded or lost during flight, the UAV still needs an experienced pilot present to handle the situation.

There are some aspects of UAV use that are unlikely to dramatically improve absent major technological breakthroughs. Flight time is one of these 
factors, and the biggest hurdle here is battery technology. Imaging is also an area where technology will improve, but also remain restricted in some ways. Imaging sensors have been getting smaller and lighter, but there are some applications that will continue to require larger, heavier lenses for optimal image quality. Scientific applications, in particular, may require more advanced, heavier equipment to obtain acceptable imagery. Also, while regulations in the US may be refined over time, the FAA's guidance is unlikely to undergo any sizable revisions shortly.

With a growing demand for SFAP imagery, the use of UAVs and tethered platforms for collecting imagery will only increase. Each of these four categories of lifting platforms is capable of collecting the necessary imagery. Knowing which platform best meets the needs of a given application will help make the process more efficient and allow operators to be more flexible in the kinds of jobs they can complete. 


\section{References}

Aber, J. S. (2016). Helium blimp for SFAP. Retrieved from: http://academic.emporia.edu/aberjame/airphoto/blimp/blimp.htm

Aber, J. S., Aber, S. W., \& Leffler, B. (2001). Challenge of infrared kite aerial photography. Transactions of the Kansas Academy of Science, 104(1-2), $18-27$.

Aber, J. S., Aber, S.W., \& Pavri, F. (2002). Unmanned small-format aerial photography from kites for acquiring large-scale, high-resolution, multiview-angle imagery. Pecora 15/Land Satellite Information IV/ISPRS Commission I/FIEOS 2002 Conference Proceedings. Nov 10-15; Denver, $\mathrm{CO}$.

Aber, J. S., \& Gałązka, D. (2000). Potential of kite aerial photography for Quaternary investigations in Poland. Geological Quarterly, 44(1), 33-38.

Aber, J. S., Sobieski, R. J., Distler, D. A., \& Nowak, M.C. (1999). Kite aerial photography for environmental site investigations in Kansas. Transactions of the Kansas Academy of Science, 102(1-2), 57-67.

Aber, J. W., \& Babb, T. A. (2018). The Challenges of Processing Kite Aerial Photography Imagery with Modern Photogrammetry Techniques. International Journal of Aviation, Aeronautics, and Aerospace, 5(2). Retrieved from: https://commons.erau.edu/ijaaa/vol5/iss $2 / 2$

Adams, S. M., \& Friedland, C. J. (2011). A survey of unmanned aerial vehicle (UAV) usage for imagery collection in disaster research and management. $9^{\text {th }}$ International Workshop on Remote Sensing for Disaster Response.

Benjamin Franklin and the Kite Experiment. (n.d.). Benjamin Franklin and the Kite Experiment | The Franklin Institute. Retrieved from: https://www.fi.edu/benjamin-franklin/kite-key-experiment

Berni, J. A. J., Zarco-Tejada, P. J., Suárez, L., \& Fereres, E. (2009). Thermal narrowband multispectral remote sensing for vegetation monitoring from an unmanned aerial vehicle. IEEE Transactions on Geoscience and Remote Sensing, 47(3), 722-738. https://doi.org/10.1109/TGRS.2008.2010457 
Beauffort, G., \& Busariez, M. (2010 Jun 25). Kite aerial photography - KAPWA Newsletter. Retrieved from:

http://kap.ced.berkeley.edu/background/kapwa1.html

Benton, C.C. (2010). Kite aerial photography - The first kite photographs. Retrieved from: http://kap.ced.berkeley.edu/background/history1.html

Best Drones with Longest Flight Times. (n.d.). Dronethusiast. Retrieved from https://www.dronethusiast.com/best-drones-with-longest-flight-times/

Boike, J., \& Yoshikawa, K. (2003). Mapping of periglacial geomorphology using kite/balloon aerial photography. Permafrost and Periglacial Processes, 14(1), 81-85. http://doi.org/10.1002/ppp.437

Bryson, M., Johnson-Roberson, M., Murphy, R.J., \& Bongiorno, D. (2013). Kite aerial photography for low-cost, ultra-high spatial resolution multi-spectral mapping of intertidal landscapes. PLOS One, 8(9).

http://doi.org/10.1371/journal.pone.0073550

CHDK Wiki. (2018). CHDK Wiki | FANDOM powered by Wikia. Retrieved from: http://chdk.wikia.com/wiki/CHDK

Conrad, K. (n.d.). KAP Kites, Flying Line, \& Accessories. Retrieved from: http://www.brooxes.com/newsite/BBKK/kitesales.html

Cornelisse, D. G. (2003). Splendid vision, unswerving purpose: Developing air power for the United States Air Force during the first century of powered flight. Department of the Air Force.

d'Oleire-Oltmanns, S., Marzolff, I., Peter, K. D., \& Ries, J. B. (2012). Unmanned aerial vehicle (UAV) for monitoring soil erosion in Morocco. Remote Sensing 4(11), 3390-3416. https://doi.org/10.3390/rs4113390

Donald, D. (2018 Mar 13). U.S. Air Force ends Predator operations. Aviation International News Online. Retrieved from https://www.ainonline.com/aviation-news/defense/2018-03-13/us-airforce-ends-predator-operations

Egels, Y. \& Kasser, M. (2004). Digital Photogrammetry. Taylor \& Francis: New York, NY. 
Eltner, A., Baumgart, P., Maas, H., \& Faust, D. (2014). Multi-temporal UAV data for automatic measurement of rill and interrill erosion on loess soil. Earth Surface Processes and Landforms 40. 741-755. https://doi.org/10.1002/esp.3673

European Commission. (2017 Jun 16). Aviation: Commission is taking the European drone sector to new heights. IP/17/1605. Retrieved from: http://europa.eu/rapid/press-release_IP-17-1605_en.htm

Federal Aviation Administration. (2013). Pack safe - Lithium ion and lithium metal batteries, spare (uninstalled). United States Department of Transportation - Federal Aviation Administration. Retrieved from: https://www.faa.gov/about/initiatives/hazmat_safety/more_info/?hazmat= 7

Federal Aviation Administration. (2017). No Drone Zone. United States Department of Transportation - Federal Aviation Administration. Retrieved from: https://www.faa.gov/uas/where_to_fly/no_drone_zone/

Federal Aviation Administration. (2018a). Operating rules, 14 C.F.R. $\S 107.31$.

Federal Aviation Administration. (2018b). Moored balloons, kites, amateur rockets, unmanned free balloons, and certain model aircraft, 14 C.F.R. $\S$ 101.

Federal Aviation Administration. (2018c). Special rule for model aircraft, 14 C.F.R. $\S 101.41$.

Federal Aviation Administration. (2018d). Small unmanned aircraft systems, 14 C.F.R. $\S 107$.

Fraser, W.R., Carlson, J.C., Duley, P.A., Holm, E.J., \& Patterson, D.L. (1999). Using kite-based aerial photography for conducting Adélie penguin censuses in Antarctica. Waterbirds: The International Journal of Waterbird Biology, 22(3), 435-440. http://doi.org/10.2307/1522120

Fioretti, J. (2017 Nov 30). EU agrees registration rules for drones, downloads of flight recordings. Reuters. Retrieved from: https://www.reuters.com/article/us-eu-drones/eu-agrees-registration-rulesfor-drones-downloads-of-flight-recordings-idUSKBN1DU2PO 
Frizot, M. (1998). Another kind of photography. In: Frizot, M. The New history of photography. Könemann Verlagsgesellschaft mbH: Köln, Germany.

Gillispie, C. G. (1983). The Montgolfier Brothers and the Invention of Aviation 1783-1784: With a Word on the Importance of Ballooning for the Science of Heat and the Art of Building Railroads. Princeton University Press: Princeton, NJ.

Gonzalez, L. F., Montes, G. A., Puig, E., Johnson, S., Mengersen, K., \& Gaston, K. J. (2016). Unmanned Aerial Vehicles (UAVs) and Artificial Intelligence Revolutionizing Wildlife Monitoring and Conservation. Sensors 16(1), 97. https://doi.org/10.3390/s16010097

Hart, C. (1982). Kites: An historical survey. New York: Frederick A. Praeger.

Jarvis, J. B. (2014 Jun 19). Unmanned Aircraft - Interim Policy (Policy Memorandum 14-05). Retrieved from: https://www.nps.gov/policy/PolMemos/PM_14-05.htm

Jenkins, D. \& Vasigh, B. (2013). The economic impact of unmanned aircraft systems integration in the United States. Association for Unmanned Vehicle Systems International. Retrieved from: http://www.auvsi.org/ourimpact/economic-report

Kreps, S. E. (2016). Drones: What everyone needs to know. New York: Oxford University Press.

Laliberte, A. S., Herrick, J. E., Rango, A., \& Winters, C. (2010). Acquisition, orthorectification, and object-based classification of unmanned aerial vehicle (UAV) imagery for rangeland monitoring. Photogrammetric Engineering \& Remote Sensing 76(6), 661-672. https://doi.org/10.14358/PERS.76.6.661

Linchant, J., Lisein, J., Semeki, J., Lejeune, P., \& Vermeulen, C. (2015). Are unmanned aircraft systems (UASs) the future of wildlife monitoing? A review of accomplishments and challenges. Mammal Review 45(4), 239252. https://doi.org/10.1111/mam.12046 
Marzolff, I., \& Poesen, J. (2009). The potential of 3D gully monitoring with GIS using high-resolution aerial photography and a digital photogrammetry system. Geomorphology, 111, 48-60. http://doi.org/10.1016/j.geomorph.2008.05.047

Mulero-Pázmány, M., Jenni-Eiermann, S., Strebel, N., Sattler, T., Negro, J. J., \& Tablado, Z. (2017). Unmanned aircraft systems as a new source of disturbance for wildlife: A systematic review. PLOS One 12(6), E0178448. https://doi.org/10.1371/journal.pone.0178448

National Park Service. (2014). Use of Unmanned Aircraft Systems (Drones) Prohibited in Yosemite National Park - Yosemite National Park (U.S. National Park Service). Retrieved from: https://www.nps.gov/yose/learn/news/use-of-unmanned-aircraft-systemsdrones-prohibited-in-yosemite-national-park.htm

Oettershagen, P., Melzer, A., Mantel, T., Rudin, K., Thomas, S., Wawrzacz, B., ... Siegwart, R. Y. (2016). Perpetual flight with a small solar-powered UAV: Flight results performance analysis and model validation. Proceedings of the 2016 IEEE Aerospace Conference (AERO 2016). 7500855. Big Sky, MT: IEEE. https://doi.org/10.1109/AERO.2016.7500855

Ohring, G. (1964). A most surprising discovery. Bulletin of the American Meteorological Society, 45(1), 12-14. Retrieved from: http://www.jstor.org/stable/26246947

Ryan, J. C., Hubbard, A. L., Box, J. E., Todd, J., Christoffersen, P., Carr, J. R., ... Snooke, N. (2015). UAV photogrammetry and structure from motion to assess calving dynamics at Stone Glacier, a large outlet draining the Greenland ice sheet. The Cryosphere, 9, 1-11. http://doi.org/10.5194/tc-9$1-2015$

Rümmler, M., Mustafa, O., Maercker, J., Peter, H., \& Esefeld, J. (2015). Measuring the influence of unmanned aerial vehicles on Adélie penguins. Polar Biology 39(7). 1329-1334. https://doi.org/10.1007/s00300-0151838-1

Scientific American. (1849). More About Balloons. Scientific American 4(26), 205. 
Smith, M.J., Chandler, J.H., \& Rose, J. (2009). High spatial resolution data acquisition for the geosciences: kite aerial photography. Earth Surface Processes and Landforms, 34, 155-161. http://doi.org/10.1002/esp.1702

Sklaver, B.A., Manangan, A., Bullard, S., Svanberg, A., \& Handzel, T. (2006). Rapid imagery through kite aerial photography in a complex humanitarian emergency. International Journal of Remote Sensing, 27(21), 4709-4714. http://doi.org/10.1080/01431160600784309

Slattery, C., \& Whittle, R. (2013). The drone started here. Air \& Space Magazine. April-May, 28-33.

Sohn, E. (2011). When lightning strikes out of a blue sky. Discovery News. Retrieved from: https://web.archive.org/web/20151101020717/http://news.discovery.com/e arth/weather-extreme-events/lightning-on-clear-day-110729.htm

Unmanned aerial vehicles. (2015, September 26). Retrieved from: https://www.economist.com/news/science-and-technology/21666118miniature-pilotless-aircraft-are-verge-becoming-commonplace-welcome

U.S. Department of Transportation. (2018, January 10). FAA Drone Registry Tops One Million [Press release]. Retrieved from:

https://www.transportation.gov/briefing-room/faa-drone-registry-tops-onemillion

Verhoeven, G.J.J. (2009). Providing an archaeological bird's-eye view - an overall picture of ground-based means to execute low-altitude aerial photography (LAAP) in archaeology. Archaeological Prospection, 16, 233-249. http://doi.org/10.1002/arp.354

Westoby, M. J., Brasington, J., Glasser, N. F., Hambrey, M. J., \& Reynolds, J. M. (2012). 'Structure-from-Motion' photogrammetry: a low-cost, effective tool for geoscience applications. Geomorphology, 179(15), 300-314. http://doi.org/10.1016/j.geomorph.2012.08.021 